Article

\title{
Always Online? Internet Addiction and Social Impairment in Psoriasis across Germany
}

\author{
Maximilian Christian Schielein ${ }^{1,2,3, *}$, Linda Tizek ${ }^{1,2,3} \mathbb{C}^{-}$, Barbara Schuster ${ }^{1,2,3} \mathbb{C}^{-}$, \\ Stefanie Ziehfreund ${ }^{1}$, Claudia Liebram ${ }^{4}{ }^{\mathbb{D}}$, Kilian Eyerich ${ }^{1,5}$ and Alexander Zink ${ }^{1, *} * \mathbb{C}$ \\ 1 Department of Dermatology and Allergy, School of Medicine, Technical University of Munich, \\ 80802 Munich, Germany; linda.tizek@tum.de (L.T.); barbara.schuster@tum.de (B.S.); \\ stefanie.ziehfreund@tum.de (S.Z.); kilian.eyerich@ki.se (K.E.) \\ 2 Biometry and Epidemiology (IBE), Department of Medical Informatics, Ludwig-Maximilians-University, \\ 81377 Munich, Germany \\ 3 Pettenkofer School of Public Health, Ludwig-Maximilians-University, 81377 Munich, Germany \\ 4 Psoriasis-Netz e.V., 13437 Berlin, Germany; redaktion@psoriasis-netz.de \\ 5 Karolinska Institutet, Department of Medicine, Unit of Dermatology and Venerology, Karolinska University \\ Hospital, 17177 Stockholm, Sweden \\ * Correspondence: maximilian.schielein@tum.de (M.C.S.); alexander.zink@tum.de (A.Z.); \\ Tel.: +49-89-4140-3176 (M.C.S.); +49-89-4140-3551 (A.Z.)
}

Received: 19 May 2020; Accepted: 7 June 2020; Published: 11 June 2020

check for updates

\begin{abstract}
With the World Health Organization (WHO) demanding further investigation of the social impairment and psychosocial burden of psoriasis, a first study identified a high prevalence of Internet addiction. The aim of this study was to assess social impairment and estimate the occurrence of Internet addiction along with depression, cigarette smoking, and alcohol dependency in individuals with psoriasis recruited online in a people-centered care approach. A cross-sectional online survey was carried out across Germany between March 2019 and June 2019. The questionnaire contained information on social impairment, smoking habits, as well as validated questionnaires on Internet addiction, depression, and alcohol dependency. Overall, 460 individuals (62.4\% female; mean age: $45.9 \pm 13.7$ years) with psoriasis were included. Of those, $406(88.3 \%)$ stated to be at least rarely socially impaired. The positive screening rate for Internet addiction was $8.5 \%$. Furthermore, $40.0 \%$ had positive screenings for depression, $17.1 \%$ for alcohol dependency, and $32.6 \%$ for daily smoking. Positive screenings for Internet addiction and alcohol dependency were substantially more frequent in individuals with psoriasis than in the German general population. In order to meet the demands of the WHO, Internet addiction could be considered as a potential comorbidity in psoriasis and a focus on people-centered care is advisable for further research.
\end{abstract}

Keywords: psoriasis; Internet addiction; people-centered care; social impairment; stigmatization

\section{Introduction}

Internet addiction is a phenomenon first appearing at the turn of the millennium that has since then begun to rise immensely in importance [1]. It was classified as the most potent problem within the revised Diagnostic and Statistical Manual of Mental Disorders (DSM) in 2013 [2]. In Germany, prevalence estimations range from $1.0 \%$ in the general population up to $3.2 \%$ in the subgroup of adolescents $[3,4]$. With regard to skin diseases, a recent study found that pathological Internet use and Internet addiction were substantially more frequent among a sample of 502 patients with psoriasis $(3.8 \%)$ than in the general population $(1.0 \%)$ [3,5].

Psoriasis is a chronic inflammatory skin disease affecting 1.2-3\% of individuals in Germany [6-8]. Patients often have an impaired quality of life and reduced happiness [8,9]. Individuals with psoriasis 
tend to avoid or reduce physical activities and often withdraw themselves from social activities [10,11] and intimate contact $[12,13]$. These social impairments are broadly individual for each patient and associated with various comorbidities [14]. Patients often suffer from a psychosocial burden due to stigmatization $[15,16]$ as well as from comorbidities such as depression and addictions $[17,18]$. Subsequently, the World Health Organization (WHO) emphasized the importance of recognizing the stigmatization in psoriasis and its potential consequences for burden of disease and mental comorbidities [19]. While reviews indicate more frequent alcohol dependency and cigarette smoking in psoriasis patients $[20,21]$, evidence on compulsive Internet use and Internet addiction remains limited to one study [5].

If treated appropriately, patients with psoriasis can benefit from highly effective therapies. Individuals treated effectively tend to have not only less severe skin lesions but also reduced depressive symptoms and social impairment [22,23]. The reduction of comorbidities and the promotion of mental health of individuals with psoriasis are essential according to the WHO [19]. However, not all patients receive therapies as recommended by guidelines [24,25], and, since not all affected individuals seek medical care, many affected individuals are not considered as psoriasis patients [26]. Hence, the WHO demands to focus on people-centered instead of patient-centered health care $[27,28]$. Despite this, most research still focuses on registries including mainly, moderately, and severely affected individuals and typical patient settings such as dermatological practices and clinics. To reach individuals outside of conventional settings, online approaches can be beneficial $[13,29]$ as many individuals, regardless of contact to a physician, search for health-related information online [30-33].

The aim of this study was therefore to assess social impairment and to estimate the occurrence of Internet addiction along with depression, smoking, and alcohol dependency among individuals with psoriasis using a people-centered online approach.

\section{Experimental Section}

\subsection{Study Design and Recruitment}

This cross-sectional study was carried out as an online survey among individuals with psoriasis in Germany from March to June 2019. The online questionnaire was distributed via an online self-help platform "Psoriasis-Netz", a patient online platform "Farbenhaut" as well as a national campaign of the "Association of the German Dermatologists" (BVDD). The project was most promoted by "Psoriasis-Netz" on their website together with current information for individuals interested in psoriasis. Its monthly e-mail newsletter was sent to 2296 registered individuals across Germany. "Farbenhaut" and the BVDD shared the questionnaire on their social media channels one month before completion of recruitment for the study.

Only individuals who stated having psoriasis diagnosed by a physician were included in the analyses. Additional exclusion criteria were the presence of implausible data or more than $20 \%$ of missing values. Electronic informed consent from each participant was acquired prior to study inclusion. All study procedures were in accordance with the Declaration of Helsinki and were reviewed as well as approved by the local ethics committee of the Technical University of Munich (reference 25/19 S).

\subsection{Questionnaire}

The study questionnaire was developed in collaboration with "Psoriasis-Netz". One dermatologist, two epidemiologists, and two members of "Psoriasis-Netz" were involved in the process. Questions were only added if they were accepted unanimously. The questionnaire was pre-tested by three researchers and three individuals affected by psoriasis and adapted according to their comments.

Participants answered questions on sociodemographic variables and their medical history, including age, gender, disease severity in general and at time of participation (self-classification as "mild", "moderate", or "severe", respectively) as well as disease duration and current utilization of 
medical care. Due to the nature of the chosen online approach, standardized reflection of disease severity using physician-based Psoriasis Area and Severity Index (PASI) or body surface affected (BSA) was not possible. In order to keep the questionnaire concise, social impairment was assessed with a one-question item asking "Does your psoriasis prevent you from pursuing certain leisure activities?", which could be answered on a five-point Likert scale ranging from "never" to "always". Participants who stated that their psoriasis prevents them from taking part in certain leisure activities were asked for the main restrictions using free-text comments. After revising the questionnaire, examples for possible answers were added ("e.g., swimming, sauna, sunbathing, ... ").

Internet addiction was assessed using the Compulsive Internet Using Scale (CIUS; Cronbach's $\alpha=0.93)[34,35]$. The questionnaire comprises 14 questions, which are to be answered on a five-point Likert-scale ranging from "never $=0$ " to "very often $=4$ ". Subsequently, the score ranges from 0 to 56. A cutoff score of 21 was used to estimate the prevalence of Internet addiction [5,35]. Additionally, participants were asked to state the days per week and hours per day spent online in their leisure time.

Depressive behavior was assessed with the International Classification of Diseases (ICD)-10-based WHO-Five Well-Being Index (WHO-5, Cronbach's $\alpha=0.88$ ) [36,37], a widely used, validated questionnaire comprising five questions on well-being. Answers range from "never" to "always" and are rated from zero to five, respectively. The resulting sum is multiplied by four, resulting in a score between 0 and 100. A cutoff value of $\leq 28$ for depression showed a sensitivity of 0.94 and a specificity of 0.83 and, therefore, was used to determine depression as a study outcome [38].

To screen for alcohol use disorder, the DSM-based CAGE-questionnaire was used [39]. It comprises questions on "cutting down", "annoyed by criticism", "guilt about drinking", and alcohol as an "eye-opener" in the morning. Questions are answered with "no" or "yes". The subsequent score ranges from zero to four. The instrument showed good test-retest reliability $(0.80-0.95)$ and the cutoff value of at least two questions answered with "yes" as a positive screening for alcohol use disorder previously showed a sensitivity of 0.71 and a specificity of 0.90 [40].

Smoking was assessed by one question: "Do you smoke cigarettes?". Participants who stated that they "never" or "seldom" smoke were classified as non-smokers. Participants who stated that they smoke daily, regardless of the stated amount, were considered smokers.

\subsection{Statistical Analyses}

As the online method of patient recruitment of this people-centered survey was explorative, study size was determined by the number of individuals recruited during a three-month time frame. Descriptive data were computed for all participants and stratified by social impairment. Group differences were calculated using unpaired t-tests or chi-square tests. Prevalence of positive screenings for Internet addiction along with those for depression, smoking, and alcohol dependency were determined. Results were stratified by gender, age (by median split; 46 years), and social impairment. To avoid confounding, possible influencing factors were assessed using univariate and multiple regression models. All factors that showed a significant association in the univariate analysis, were entered in the multiple regression model with backward selection. Independent variables included age, gender, disease duration, utilization of medical care, disease severity at time of study participation, severity in general, and social impairment. Odds ratios (OR) and respective $95 \%$ confidence intervals (95\% CIs) were calculated. To analyze activities avoided due to psoriasis, free-text answers were categorized using an inductive analyzing procedure. Categories were descriptively quantified. Additionally, quantities of the 50 most commonly used words were visualized while excluding nonspecific words such as "I", "with", or "do". IBM SPSS Statistics (Version 25, IBM Corporation, Armonk, NY, USA) was used for all analyses and alpha was set at 0.05 .

\section{Results}

A total of 466 individuals with psoriasis participated in this study. Of these, six were excluded due to implausible data, resulting in a total of 460 participants being analyzed. The mean age was 
$45.9 \pm 13.7$ years and $62.4 \%(n=287)$ of the participants were female. The mean duration of disease was $21.0 \pm 14.7$ years and $22.8 \%(n=105)$ of the participants were currently not in medical care. About half of the participants stated to have a moderate disease severity both at the time of study participation $(55.0 \% ; n=253)$ and in general $(56.3 \% ; n=259)$. When comparing general and current disease severity, $32.8 \%(n=151)$ of the participants stated that their psoriasis was better at the time of study participation, while $13.0 \%(n=60)$ indicated a worse disease severity (Table 1$)$.

Table 1. Characteristics of study participants in total and stratified by influence of psoriasis on avoiding free-time activities.

\begin{tabular}{|c|c|c|c|c|}
\hline & \multirow[b]{2}{*}{$\begin{array}{c}\text { Total } \\
(n=460)\end{array}$} & \multicolumn{2}{|c|}{ Psoriasis is Preventing Leisure Activities } & \multirow[b]{2}{*}{$p$-Value } \\
\hline & & $\begin{array}{l}\text { Never or Rarely } \\
\quad(n=130)\end{array}$ & $\begin{array}{l}\text { Sometimes, Frequently, } \\
\text { or Always }(n=330)\end{array}$ & \\
\hline \multicolumn{5}{|c|}{ Age (years) } \\
\hline (Mean, SD) & $45.9 \pm 13.7$ & $46.7 \pm 14.1$ & $45.6 \pm 13.6$ & 0.426 \\
\hline $\begin{array}{l}\text { Age group } \\
<46\end{array}$ & $222(48.3 \%)$ & $62(47.7 \%)$ & $160(48.5 \%)$ & \multirow[t]{2}{*}{0.878} \\
\hline $\begin{array}{l}\text { Age group } \\
\geq 46\end{array}$ & $238(51.7 \%)$ & $68(52.3 \%)$ & $170(51.5 \%)$ & \\
\hline \multicolumn{5}{|c|}{ Gender; $n(\%)$} \\
\hline Female & $287(62.4 \%)$ & $86(66.2 \%)$ & $201(60.9 \%)$ & \multirow{2}{*}{0.296} \\
\hline Male & $173(37.6 \%)$ & $44(33.8 \%)$ & $129(39.1 \%)$ & \\
\hline \multicolumn{5}{|c|}{ Duration of psoriasis (years) } \\
\hline (Mean, SD) & $21.0 \pm 14.7$ & $21.9 \pm 15.1$ & $20.7 \pm 14.6$ & 0.416 \\
\hline \multicolumn{5}{|c|}{ Currently in medical care; $n(\%)$} \\
\hline Yes & $355(77.2 \%)$ & $95(73.1 \%)$ & $260(78.8 \%)$ & \multirow{2}{*}{0.189} \\
\hline No & $105(22.8 \%)$ & $35(26.9 \%)$ & $70(21.2 \%)$ & \\
\hline \multicolumn{5}{|c|}{ Severity at the time of study participation; $n(\%)$} \\
\hline Mild & $102(22.2 \%)$ & $47(36.2 \%)$ & $55(16.7 \%)$ & \\
\hline Moderate & $253(55.0 \%)$ & $74(56.9 \%)$ & $179(54.2 \%)$ & $<0.001$ \\
\hline Severe & $105(22.8 \%)$ & $9(6.9 \%)$ & $96(29.1 \%)$ & \\
\hline \multicolumn{5}{|c|}{ Severity in general; $n(\%)$} \\
\hline Mild & $37(8.0 \%)$ & $22(16.9 \%)$ & $15(4.5 \%)$ & \multirow{3}{*}{$<0.001$} \\
\hline Moderate & $259(56.3 \%)$ & $83(63.8 \%)$ & $176(53.3 \%)$ & \\
\hline Severe & $164(35.7 \%)$ & $25(19.2 \%)$ & $139(42.1 \%)$ & \\
\hline \multicolumn{5}{|c|}{ Severity at study participation compared to severity in general; $n(\%)$} \\
\hline Worse & $60(13.0 \%)$ & $12(9.2 \%)$ & $48(14.5 \%)$ & \multirow{3}{*}{0.225} \\
\hline Equal & $249(54.1 \%)$ & $77(59.2 \%)$ & $172(52.1 \%)$ & \\
\hline Better & $151(32.8 \%)$ & $41(31.5 \%)$ & $110(33.3 \%)$ & \\
\hline
\end{tabular}

$\mathrm{SD}=$ standard deviation.

\subsection{Social Impairment}

Overall, $330(71.7 \%)$ stated that their psoriasis at least sometimes prevents them from certain leisure activities. Of these, $124(27.0 \%)$ individuals answered this question with "frequently" and 92 $(20.0 \%)$ with "always". Participants indicating that their psoriasis prevents them at least sometimes from certain leisure activities reported a higher rate of severe disease characteristics at the time of study participation $(29.1 \%$ vs. $6.9 \% ; p<0.001)$ and in general $(42.1 \%$ vs. $19.2 \% ; p<0.001)$ than participants who indicated no or rare impairment (Table 1 ).

Furthermore, $406(88.3 \%)$ participants stated that their psoriasis at least rarely prevents them from any leisure activity. When asked which leisure activities were impaired with an open question, 394 participants $(97.0 \%)$ provided 552 answers. After qualitatively categorizing all given answers, "swimming" ( $n=273 ; 67.2 \%$; e.g., "Swimming in public pools. The chlorine burns the skin."), "sport" 
( $n=93 ; 22.9 \%$; e.g., "I can't go jogging anymore as my knees were destroyed by psoriatic arthritis."), and "stigmatization and appearance" ( $n=49 ; 12.1 \%$; e.g., "Whenever I can't put on anything long enough to hide my disease in public") were the three most mentioned categories (Table 2). Furthermore, many answers indicated a reduction in social contacts. For example, people used expressions such as "meeting new people" and "any activity among people is unpleasant because the strong itching leads to scratching and leaving dandruff everywhere". Many individuals also mentioned abstaining from activities that could exacerbate their symptoms, such as "drinking/eating/partying-all because of the fear of worsening condition following the consumption of unhealthy food/alcohol". Reasons given widely differ within the individuals and the 50 most commonly used words show a multifaceted sense of loss and preoccupation with daily life for participants due to psoriasis (Figure 1).

Table 2. Inductive categories of free-text answers on what leisure activities were avoided due to psoriasis. Quantity, two examples, and respective participant characteristics per category.

\begin{tabular}{|c|c|c|c|}
\hline Category & Count $n(\%)$ & Example & Participant (Gender, Age) \\
\hline \multirow[t]{2}{*}{ Swimming } & \multirow[t]{2}{*}{$273(67.2 \%)$} & $\begin{array}{l}\text { "Sauna and swimming pool, but only } \\
\text { because of the expected looks on the } \\
\text { affected areas" }\end{array}$ & Woman, 32 years \\
\hline & & $\begin{array}{l}\text { "Swimming in public pools. The chlorine } \\
\text { burns the skin". }\end{array}$ & Man, 39 years \\
\hline \multirow[t]{2}{*}{ Sport } & \multirow[t]{2}{*}{$93(22.9 \%)$} & $\begin{array}{l}\text { "I can't go jogging anymore as my knees } \\
\text { were destroyed by psoriatic arthritis". }\end{array}$ & Man, 32 years \\
\hline & & "Running" & Woman, 51 years \\
\hline \multirow{2}{*}{$\begin{array}{l}\text { Stigmatization } \\
\text { and appearance }\end{array}$} & \multirow[t]{2}{*}{$49(12.1 \%)$} & $\begin{array}{l}\text { "Whenever I can't put on anything long } \\
\text { enough to hide my disease in public" }\end{array}$ & Woman, 50 years \\
\hline & & "Any activity requiring short clothing" & Woman, 21 years \\
\hline \multirow{2}{*}{ Sauna } & \multirow{2}{*}{$32(7.9 \%)$} & "Sauna, bathing" & Man, 73 years \\
\hline & & "Sauna, swimming, nudism" & Woman, 57 years \\
\hline \multirow{2}{*}{ Sunbathing } & \multirow{2}{*}{$30(7.4 \%)$} & "Sunbathing at the lake" & Man, 57 years \\
\hline & & "Sunbathing at the beach" & Man, 30 years \\
\hline \multirow{2}{*}{$\begin{array}{l}\text { Movements } \\
\text { and walking }\end{array}$} & \multirow{2}{*}{$28(6.9 \%)$} & "Going for a walk" & Woman, 52 years \\
\hline & & "Roughhousing with my son" & Man, 34 years \\
\hline \multirow[t]{2}{*}{$\begin{array}{l}\text { Going out and } \\
\text { meeting friends }\end{array}$} & \multirow[t]{2}{*}{$26(6.4 \%)$} & $\begin{array}{l}\text { "Any activity among people is unpleasant } \\
\text { because the strong itching leads to } \\
\text { scratching and leaving } \\
\text { dandruff everywhere". }\end{array}$ & Woman, 27 years \\
\hline & & "Visiting restaurants with friends" & Man, 38 years \\
\hline \multirow{2}{*}{ Other } & \multirow{2}{*}{$21(5.2 \%)$} & "Everything you need hands for" & Woman, 67 years \\
\hline & & "Living" & Man, 38 years \\
\hline
\end{tabular}

\subsection{Internet Addiction}

Participants reported spending $21.6 \pm 12.5 \mathrm{~h}$ per week online excluding time at work. About four out of five participants stated being online for private reasons every day $(n=381 ; 82.8 \%)$. Overall, $8.5 \%(n=39)$ of all participants were screened positive for Internet addiction, with no significant difference in gender (female: $8.5 \%$ vs. male: $8.7 \%, p=0.935$ ), age ( $<46$ years: 9.1 vs. $\geq 46$ years: $8.0 \%$, $p=0.660$ ), and social impairment due to psoriasis ("Never or rarely": $8.5 \%$ vs. "Sometimes, frequently, or always": $8.5 \%, p=0.997$; Figure 2, Table A1). 


\section{Impairment in leisure activities due to psoriasis}

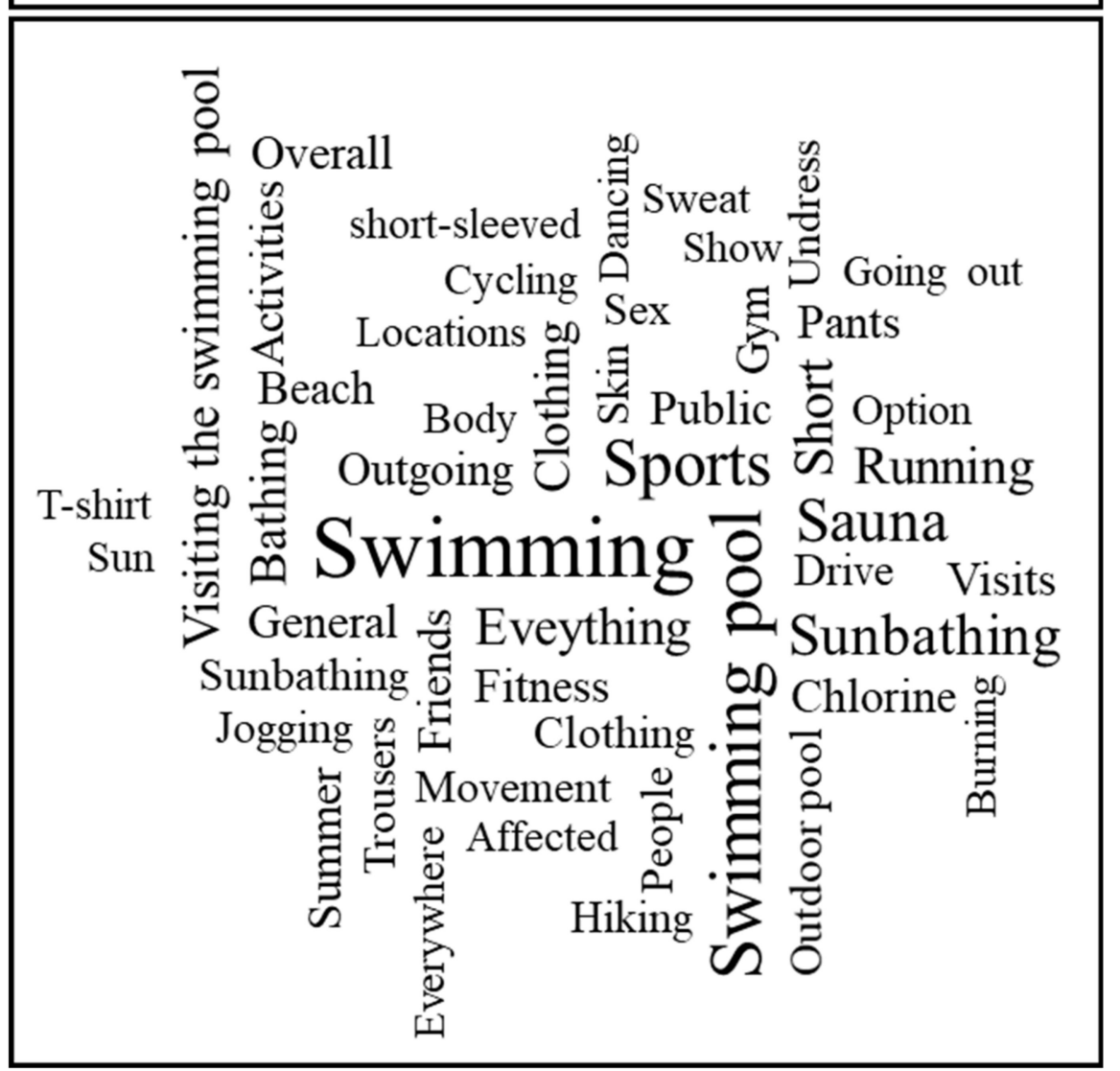

Figure 1. The 50 most common words in free-text answers on the question, which leisure activities were prevented by psoriasis. Words were ranked by frequency. Font size (fs) equals the sweeping break of the third root of word's rank ( $\mathrm{rx}$ ) times maximal font size $\left(\mathrm{fs}_{\max }\right)\left[\mathrm{fs}=\mathrm{fs}_{\max }{ }^{*} \mathrm{rx}^{-1 / 3}\right]$. As some words cannot be translated verbatim and free-text answers were given in German, some words are separated in two or more or appear as duplicates.

\subsection{Depression, Smoking, and Drinking}

Depressive tendencies were found in $40.0 \%(n=180)$ of the participants (Figure 1). Social impairment due to psoriasis (at least "sometimes") was associated with a higher proportion of positive screening results for depression $(45.8 \%$ vs. $25.2 \% ; p<0.001)$. Furthermore, $32.6 \%(n=150)$ of all individuals stated to smoke cigarettes daily, and $17.1 \%(n=77)$ were screened positive for alcohol addiction. More women reported a daily smoking habit $(38.3 \%$ vs. $23.1 \% ; p=0.001$; Figure 1$)$, while more men were screened positive for alcohol addiction $(25.9 \%$ vs. $11.8 \% ; p<0.001)$. Additionally, younger participants more frequently reported smoking cigarettes daily $(41.4 \%$ vs. $24.4 \% ; p<0.001)$. These differences remained significant when controlled in a multiple regression model, resulting in ORs of 2.13 (95\% CI: 1.36; 3.34) for women and 0.96 (95\% CI: 0.95; 0.98) for age (Table A2). 


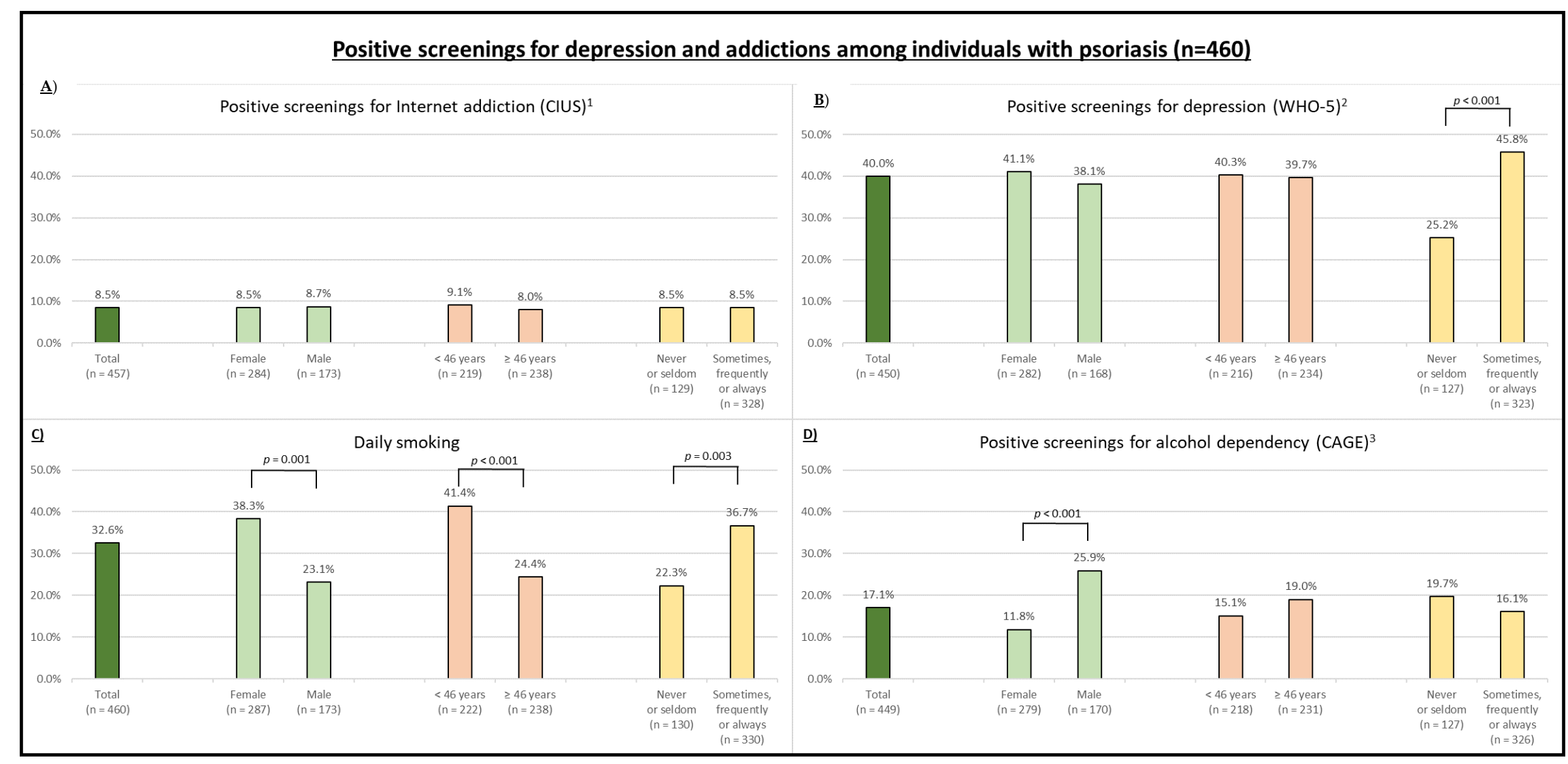

Figure 2. Positive screenings for (A) Internet addiction, (B) depression, (C) cigarette smoking, and (D) alcohol dependency. Positive screenings are stratified by gender, age (median split), and social impairment. ${ }^{1}$ Measured using the Compulsive Internet Using Scale (CIUS; cutoff: $\geq 21$; range: $\left.0-56\right) .{ }^{2}$ Measured using the World Health Organization (WHO)-Five Well-Being Index (WHO-5) questionnaire (cutoff: $\leq 29$; range: $0-100$ ). ${ }^{3}$ Measured using the CAGE questionnaire (cutoff: $\geq 2$; range: $0-4$ ). 


\section{Discussion}

This study aimed to characterize social impairment and estimate the occurrence of Internet addiction along with depression, smoking, and alcohol dependency in individuals with psoriasis recruited via an online, people-centered care approach. Many participants indicated an impairment due to their psoriasis, with swimming and sports being the most commonly mentioned fields of daily life being avoided. Given reasons often focused on stigmatization and pain. Furthermore, a high positive screening rate for Internet addiction and alcohol dependency was found.

\subsection{Social Impairment}

Overall, $88.3 \%$ of participants indicated that their psoriasis prevents them from leisure activities and meeting other people. Thereby, individuals with more social impairment reported higher self-perceived disease severity. This finding is in line with a previous study, which found that individuals with moderate or severe disease severity engaged approximately $30 \%$ less in leisure activities than healthy controls did; no difference was observed for participants with little or no disease activity [10]. In our study, we not only found that people avoided specific leisure activities such as swimming and sports but that they also felt stigmatized. This confirms previous findings that stigmatization of skin lesions was associated with social impairment [16]. Most of the participants mentioned avoiding swimming. However, it should be noted that examples for leisure activities such as "Swimming, sauna, sunbathing, ..." " were provided as suggestions to give participants ideas for possible answers, potentially resulting in biased free-text answers. The high number of mentions for swimming, however, reflect a problem identified decades ago [41]. In 1989, a study on 104 psoriasis patients found that $72 \%$ of patients avoided swimming, $60 \%$ avoided sunbathing, and $40 \%$ avoided sports. Although sunbathing was also mentioned as an example in this study, it was mentioned less frequently in this sample, while swimming remains an often avoided activity for affected individuals [41]. The stated reasons of shame, stigmatization, and physical sensations such as burning and itching are in line with previous literature [10,41]. The fact that patients still abstain from activities such as swimming because of possible stigmatization emphasizes the importance of current efforts to reduce stigmatization in psoriasis $[15,16]$, which follows the call for action outlined by the WHO [19]. Another point that might be addressed in future research is a possible connection between skin and joint pain as well as itch, and social impairment. Skin pain is an often prevalent symptom [42] and was also frequently reported in the free-text answers.

\subsection{Internet Addiction}

Positive screening rates for Internet addiction exceeded those reported in the literature [3-5,43]. In comparison to a German representative study among adolescents, this study's results were considerably higher ( $8.5 \%$ vs. $3.2 \%$ ) [4]. This is surprising, considering the difference in mean age (45.9 years vs. 14.9 years) and tendency for Internet addiction to occur in younger individuals and to decrease with age [3]. Even if we were to consider a higher cutoff value of 28, our detected prevalence of Internet addiction was higher (3.2\%) than the prevalence of $1.0 \%$ in another German study among 8132 adolescents and adults (mean age: 39.9 years) [3]. Although a third study also used online recruitment via Facebook groups, they only detected a prevalence of $1.2 \%$ of Internet addiction in 245 regular Internet users [43]. Lastly, the prevalence of positive screening results also outnumbered the prevalence among 502 psoriasis patients recruited from various dermatological practices and clinics throughout southern Germany (8.5\% vs. 3.6\%) [5]. Since our results on Internet addiction exceed all previous reported numbers, this could imply that by recruiting participants online and via patient platforms as well as a nationwide physician-lead campaign, we were able to reach a highly vulnerable subgroup of individuals with psoriasis. As another study by Megna et al. found higher signs of inflammation in patients with psoriatic arthritis who practice smartphone overuse [44], future studies should include patient stratification by presence of psoriatic arthritis and differentiation between online 
and smart phone addiction. This is, however, one of the first studies to investigate Internet addiction in psoriasis and further investigation should follow.

\subsection{Depression, Smoking, and Alcohol Dependency}

Our detected value for positive screenings for depression is similar to one of the highest prevalence rates reported by a systematic review on depression in patients with psoriasis (questionnaire-based prevalence: $13.8-39.2 \%$ ) [17]. The high rate of depression in our study might be explained by the fact that a people-centered care approach was used instead of a patient-centered approach. This could be beneficial in reaching especially vulnerable subgroups of affected individuals. In accordance with preliminary studies in patients with psoriasis $[5,18,20,21]$ and compared to a representative German sample, individuals with psoriasis reported a higher prevalence of daily smoking (32.6\% vs. $15.1 \%$ ) [45] and alcohol dependency (17.1\% vs. 3.1\%) [45]. The gender distribution for smokers was contrary to that of the general population in which men are more likely to smoke daily than women [45]. Positive screenings for alcohol dependency (17.1\%) also exceeded values reported in two recent German studies in patients with psoriasis $(8.6-13.5 \%)[5,18]$. Possible explanations might include the anonymous environment of an online survey, a more vulnerable sample in this study, or both.

\subsection{Limitations and Strengths}

There are some study limitations. As this was an online survey, the truthfulness of participant answers cannot be verified and prevalences were estimated using screening tools, not diagnoses. Additionally, due to the anonymity provided by the online design of this study, social desirability bias could have been reduced. While this is desirable, it makes comparison with previous studies in medical settings more difficult. Selection bias must be taken into account when considering the generalizability of these findings. Mainly individuals receiving information, newsletters, or social media updates from the multiplier institutions were reached. Individuals who are not engaging with online content related to psoriasis, who are participating in other organizations, or who do not have an Internet connection were highly unlikely to participate in our study. However, this might have also led to an especially vulnerable subgroup of affected individuals, which can be desirable when evaluating mental and social impairment. Those with a high disease burden might be more likely to search for further information online and therefore have may have a higher chance of receiving a study invitation through a multiplier organization. Since a high proportion of participants in this study were not currently in medical care, this online-based recruitment strategy allowed us to reach a unique group of individuals, who may not have been considered in traditional clinical trials and registries, further showing the strengths of online outreach. This can broaden the horizon of dermatological research and strengthen people-centered care [29].

\section{Conclusions}

The study implicates that social impairment and Internet addiction are high among individuals with psoriasis recruited via patient networks in a people-centered care and online approach. Positive screening results for Internet addiction and the other mental health variables exceeded values found for the general population. The findings on social impairment and addictions emphasize the importance of mental burden in psoriasis [19] and, therefore, strengthen evidence on the need for programs to reduce stigmatization $[15,16]$. Internet addiction was confirmed as an aspect of mental health that should be considered in further research on individuals with psoriasis. Ultimately, the results indicate that inclusion of online self-help platforms and their users in health care research could be a key element in promoting people-centered and not only patient-centered care.

Author Contributions: Conceptualization, M.C.S., L.T., B.S., S.Z., C.L., K.E., and A.Z.; methodology, M.C.S., B.S., C.L., and A.Z.; software, M.C.S. and B.S.; validation, L.T. and S.Z.; investigation, M.C.S., L.T., B.S., S.Z., C.L., K.E., and A.Z.; data curation, M.C.S. and B.S.; writing—original draft preparation, M.C.S.; writing-review and editing, M.C.S., L.T., B.S., S.Z., C.L., K.E., and A.Z.; visualization, M.C.S. and L.T.; supervision, K.E. and A.Z.; 
project administration, M.C.S., B.S., C.L., and A.Z. All authors have read and agreed to the published version of the manuscript.

Funding: This research received no external funding.

Acknowledgments: The authors want to thank all participating individuals with psoriasis and all multiplier institutions (Psoriasis Netz, Farbenhaut, and the BVDD) involved. Furthermore, we want to thank Alphina Kain for bilingual translation of free-text answers and English editing.

Conflicts of Interest: M.C.S. was financially supported for the presentation of scientific posters and/or received speaker's honoraria by Novartis Pharma GmbH and Janssen-Cilag. L.T. and B.S. were financially supported for the presentation of scientific posters and received unrestricted research grants by Novartis Pharma GmbH. S.Z. was financially supported for the presentation of scientific posters by Novartis Pharma GmbH. C.L. is a member and in charge of the non-profit online self-help network "Psoriasis Netz". K.E. received honoraria of or has been advisory board member at Abbvie, BMS Lilly, Janssen, Novartis, Sanofi, UCB, Leo. A.Z. has been an advisor and/or received speaker's honoraria and/or received grants and/or participated in clinical trials of the following companies with psoriasis products: AbbVie, Almirall, Amgen, Celgene, Eli Lilly, Janssen-Cilag, Novartis Pharma GmbH. 


\section{Appendix A}

Table A1. Differences in positive screenings for depression, daily smoking, alcohol dependency, and Internet addiction when stratified by gender, age (median split), and social impairment.

\begin{tabular}{|c|c|c|c|c|c|c|c|c|c|c|c|}
\hline & & \multirow[b]{2}{*}{ Total $(n=460)$} & \multicolumn{2}{|c|}{ Gender } & \multirow[b]{2}{*}{$p$-Value } & \multicolumn{2}{|c|}{ Age } & \multirow[b]{2}{*}{$p$-Value } & \multicolumn{2}{|c|}{$\begin{array}{c}\text { Psoriasis is Preventing Leisure } \\
\text { Activities }\end{array}$} & \multirow[b]{2}{*}{$p$-Value } \\
\hline & & & $\begin{array}{c}\text { Female } \\
(n=287)\end{array}$ & $\begin{array}{c}\text { Male } \\
(n=173)\end{array}$ & & $\begin{array}{l}<46 \text { years } \\
(n=222)\end{array}$ & $\begin{array}{l}\geq 46 \text { years } \\
(n=238)\end{array}$ & & $\begin{array}{l}\text { Never or Rarely } \\
\quad(n=130)\end{array}$ & $\begin{array}{c}\text { Sometimes, } \\
\text { Frequently, or } \\
\text { Always }(n=330)\end{array}$ & \\
\hline \multirow{3}{*}{$\begin{array}{c}\text { Internet } \\
\text { addiction }{ }^{3} ; n \\
(\%)\end{array}$} & Yes & $39(8.5 \%)$ & $24(8.5 \%)$ & $15(8.7 \%)$ & \multirow{3}{*}{0.935} & $20(9.1 \%)$ & $19(8.0 \%)$ & \multirow{3}{*}{0.660} & $11(8.5 \%)$ & 28 (8.5\%) & \multirow{3}{*}{0.997} \\
\hline & No & $418(91.5 \%)$ & $260(91.5 \%)$ & $158(91.3 \%)$ & & $199(90.9 \%)$ & $219(92.0 \%)$ & & $118(91.5 \%)$ & $300(91.5 \%)$ & \\
\hline & missing & 3 & 3 & 0 & & 3 & 0 & & 1 & 2 & \\
\hline \multirow{3}{*}{$\begin{array}{c}\text { Depression }{ }^{1} ; n \\
(\%)\end{array}$} & Yes & $180(40.0 \%)$ & $116(41.1 \%)$ & $64(38.1 \%)$ & \multirow{3}{*}{0.524} & $87(40.3 \%)$ & $93(39.7 \%)$ & \multirow{3}{*}{0.908} & $32(25.2 \%)$ & $148(45.8 \%)$ & \multirow{3}{*}{$<0.001$} \\
\hline & No & $270(60.0 \%)$ & $166(58.9 \%)$ & $104(61.9 \%)$ & & $129(59.7 \%)$ & $141(60.3 \%)$ & & $95(74.8 \%)$ & $175(54.2 \%)$ & \\
\hline & missing & 10 & 5 & 5 & & 6 & 4 & & 3 & 7 & \\
\hline \multirow{3}{*}{$\begin{array}{c}\text { Alcohol } \\
\text { dependency } \\
n(\%)\end{array}$} & Yes & $77(17.1 \%)$ & $33(11.8 \%)$ & $44(25.9 \%)$ & \multirow{3}{*}{$<0.001$} & $33(15.1 \%)$ & $44(19.0 \%)$ & \multirow{3}{*}{0.272} & $25(19.7 \%)$ & $52(16.1 \%)$ & \multirow{3}{*}{0.371} \\
\hline & No & $372(82.9 \%)$ & $246(88.2 \%)$ & $126(74.1 \%)$ & & $185(84.9 \%)$ & $187(81.0 \%)$ & & $102(80.3 \%)$ & $270(83.9 \%)$ & \\
\hline & missing & 11 & 8 & 3 & & 4 & 7 & & 7 & 4 & \\
\hline \multirow{3}{*}{$\begin{array}{l}\text { Smoking daily; } \\
\quad n(\%)\end{array}$} & Yes & $150(32.6 \%)$ & $110(38.3 \%)$ & 40 (23.1\%) & \multirow{3}{*}{0.001} & $92(41.4 \%)$ & $58(24.4 \%)$ & \multirow{3}{*}{$<0.001$} & $29(22.3 \%)$ & $121(36.7 \%)$ & \multirow{3}{*}{0.003} \\
\hline & No & $310(67.4 \%)$ & 177 (61.7\%) & $133(76.9 \%)$ & & $130(58.6 \%)$ & $180(75.6 \%)$ & & $101(77.7 \%)$ & 209 (63.3\%) & \\
\hline & missing & 0 & 0 & 0 & & 0 & 0 & & 0 & 0 & \\
\hline
\end{tabular}

${ }^{1}$ Measured using the Compulsive Internet Using Scale (CIUS; cutoff: $\geq 21$; range: 0-56). ${ }^{2}$ Measured using the WHO-Five Well-Being Index (WHO-5) questionnaire (cutoff: $\leq 29$; range: $0-100) .{ }^{3}$ Measured using the CAGE questionnaire (cutoff: $\geq 2$; range: $0-4$ ). 
Table A2. Associated factors for positive screenings for depression, daily smoking of tobacco as well as alcohol and Internet addiction. Results as crude and adjusted odds ratios.

\begin{tabular}{|c|c|c|c|}
\hline Dependent Variable & Independent Variables (Reference) & $\begin{array}{l}\text { Crude OR } \\
(95 \% \text { CI })\end{array}$ & $\begin{array}{l}\text { Adjusted OR } \\
(95 \% \mathrm{CI})\end{array}$ \\
\hline \multirow{11}{*}{ Internet addiction $^{1}$} & Age & $0.98(0.96-1.01)$ & - \\
\hline & Gender (male) & $0.97(0.50-1.91)$ & - \\
\hline & Duration of psoriasis & $0.97(0.95-1.00)$ & $0.97(0.95-1.00)$ \\
\hline & Currently in medical care (yes) & $0.99(0.46-2.17)$ & - \\
\hline & $\begin{array}{l}\text { Severity at the time of study } \\
\text { participation (mild) }\end{array}$ & - & - \\
\hline & moderate & $1.34(0.56-3.24)$ & - \\
\hline & severe & $1.29(0.46-3.60)$ & - \\
\hline & Severity in general (mild) & - & - \\
\hline & moderate & $0.54(0.19-1.53)$ & - \\
\hline & severe & $0.61(0.20-1.80)$ & - \\
\hline & Social impairment (never or rarely) & $1.00(0.48-2.08)$ & - \\
\hline \multirow{11}{*}{ Depression $^{2}$} & Age & $0.99(0.98-1.01)$ & - \\
\hline & Gender (male) & $1.14(0.77-1.68)$ & - \\
\hline & Duration of psoriasis & $0.98(0.97-1.00)$ & $0.98(0.97-1.00)$ \\
\hline & Currently in medical care (yes) & $1.32(0.84-2.09)$ & - \\
\hline & $\begin{array}{l}\text { Severity at the time of study } \\
\text { participation (mild) }\end{array}$ & - & - \\
\hline & moderate & $1.53(0.92-2.52)$ & $1.34(0.80-2.25)$ \\
\hline & severe & $2.77(1.55-4.94)$ & $2.13(1.16-3.91)$ \\
\hline & Severity in general (mild) & - & - \\
\hline & moderate & $1.11(0.53-2.31)$ & - \\
\hline & severe & $2.08(0.98-4.43)$ & - \\
\hline & Social impairment (never or rarely) & $2.51(1.59-3.96)$ & $2.12(1.32-3.42)$ \\
\hline \multirow{11}{*}{ Daily smoking } & Age & $0.96(0.95-0.98)$ & $0.96(0.95-0.98)$ \\
\hline & Gender (male) & $2.07(1.35-3.16)$ & $2.13(1.36-3.34)$ \\
\hline & Duration of psoriasis & $0.98(0.96-0.99)$ & - \\
\hline & Currently in medical care (yes) & $0.96(0.60-1.52)$ & - \\
\hline & $\begin{array}{l}\text { Severity at the time of study } \\
\text { participation (mild) }\end{array}$ & - & - \\
\hline & moderate & $1.36(0.81-2.26)$ & - \\
\hline & severe & $1.71(0.95-3.09)$ & - \\
\hline & Severity in general (mild) & - & - \\
\hline & moderate & $2.97(1.12-7.89)$ & $3.40(1.24-9.31)$ \\
\hline & severe & $3.99(1.48-10.78)$ & $4.58(1.62-12.96)$ \\
\hline & Social impairment (never or rarely) & $2.02(1.26-3.23)$ & $1.77(1.07-2.94)$ \\
\hline
\end{tabular}


Table A2. Cont.

\begin{tabular}{|c|c|c|c|}
\hline Dependent Variable & Independent Variables (Reference) & $\begin{array}{l}\text { Crude OR } \\
(95 \% \text { CI })\end{array}$ & $\begin{array}{l}\text { Adjusted OR } \\
(95 \% \text { CI })\end{array}$ \\
\hline \multirow{11}{*}{ Alcohol dependency ${ }^{3}$} & Age & $1.01(0.99-1.03)$ & - \\
\hline & Gender (male) & $0.34(0.23-0.63)$ & $0.34(0.23-0.63)$ \\
\hline & Duration of psoriasis & $1.01(1.00-1.03)$ & - \\
\hline & Currently in medical care (yes) & $1.08(0.60-1.94)$ & - \\
\hline & $\begin{array}{l}\text { Severity at the time of study } \\
\text { participation (mild) }\end{array}$ & - & - \\
\hline & moderate & $1.71(0.88-3.31)$ & - \\
\hline & severe & $1.10(0.49-2.48)$ & - \\
\hline & Severity in general (mild) & - & - \\
\hline & moderate & $2.76(0.82-9.37)$ & - \\
\hline & severe & $1.86(0.53-6.57)$ & - \\
\hline & Social impairment (never or rarely) & $0.79(0.46-1.33)$ & - \\
\hline
\end{tabular}

$\mathrm{OR}=$ odds ratio; $95 \% \mathrm{CI}=95 \%$ confidence interval; bold values represent significant results at alpha $0.05 .{ }^{1}$ Measured using the Compulsive Internet Using Scale (CIUS; cutoff: $\geq 21$; range: $0-56$ ). ${ }^{2}$ Measured using the WHO-Five Well-Being Index (WHO-5) questionnaire (cutoff: $\leq 29$; range: $0-100$ ). ${ }^{3}$ Measured using the CAGE questionnaire (cutoff: $\geq 2$; range: $0-4$ ).

\section{References}

1. Young, K.S. The evolution of Internet addiction. Addict. Behav. 2017, 64, 229-230. [CrossRef]

2. American Psychiatric Association. Diagnostic and Statistical Manual of Mental Disorders, 5th ed.; International Version; American Psychiatric Association: Arlington, VA, USA, 2013.

3. Rumpf, H.-J.; Vermulst, A.A.; Bischof, A.; Kastirke, N.; Gürtler, D.; Bischof, G.; Meerkerk, G.-J.; John, U.; Meyer, C. Occurence of internet addiction in a general population sample: A latent class analysis. Eur. Addict. Res. 2014, 20, 159-166. [CrossRef]

4. Wartberg, L.; Kriston, L.; Kammerl, R.; Petersen, K.-U.; Thomasius, R. Prevalence of pathological internet use in a representative German sample of adolescents: Results of a latent profile analysis. Psychopathology 2015, 48, 25-30. [CrossRef] [PubMed]

5. Schielein, M.C.; Tizek, L.; Knobloch, L.; Maaßen, D.; Biedermann, T.; Zink, A. Psoriasis and addictions: Assessing mental health in a cross-sectional study across Germany. under review.

6. Michalek, I.M.; Loring, B.; John, S.M. A systematic review of worldwide epidemiology of psoriasis. J. Eur. Acad. Dermatol. Venereol. 2017, 31, 205-212. [CrossRef] [PubMed]

7. Tizek, L.; Schielein, M.C.; Seifert, F.; Biedermann, T.; Böhner, A.; Zink, A. Skin diseases are more common than we think: Screening results of an unreferred population at the Munich Oktoberfest. J. Eur. Acad. Dermatol. Venereol. 2019, 33, 1421-1428. [CrossRef] [PubMed]

8. Greb, J.E.; Goldminz, A.M.; Elder, J.T.; Lebwohl, M.G.; Gladman, D.D.; Wu, J.J.; Mehta, N.N.; Finlay, A.Y.; Gottlieb, A.B. Psoriasis. Nat. Rev. Dis. Primers 2016, 2, 16082. [CrossRef]

9. Schuster, B.; Ziehfreund, S.; Albrecht, H.; Spinner, C.D.; Biedermann, T.; Peifer, C.; Zink, A. Happiness in dermatology: A holistic evaluation of the mental burden of skin diseases. J. Eur. Acad. Dermatol. Venereol. 2019. [CrossRef]

10. Do, Y.K.; Lakhani, N.; Malhotra, R.; Halstater, B.; Theng, C.; Østbye, T. Association between psoriasis and leisure-time physical activity: Findings from the National Health and Nutrition Examination Survey. J. Dermatol. 2015, 42, 148-153. [CrossRef]

11. Kouris, A.; Platsidaki, E.; Kouskoukis, C.; Christodoulou, C. Psychological parameters of psoriasis. Psychiatriki 2017, 28, 54-59. [CrossRef]

12. Da Silva, N.; von Stülpnagel, C.; Langenbruch, A.; Danckworth, A.; Augustin, M.; Sommer, R. Disease burden and patient needs and benefits in anogenital psoriasis: Developmental specificities for person-centred healthcare of emerging adults and adults. J. Eur. Acad. Dermatol. Venereol. 2019. [CrossRef] [PubMed] 
13. Schielein, M.C.; Tizek, L.; Schuster, B.; Ziehfreund, S.; Biedermann, T.; Zink, A. Genital psoriasis and associated factors of sexual avoidance-A people-centered cross-sectional study in Germany. Acta Derm Venerol. 2020. [CrossRef]

14. Auker, L.; Cordingley, L.; Pye, D.R.; Griffiths, C.E.M.; Young, H.S. What are the barriers to physical activity in patients with chronic plaque psoriasis? Br. J. Dermatol. 2020. [CrossRef] [PubMed]

15. Augustin, M.; Mrowietz, U.; Luck-Sikorski, C.; von Kiedrowski, R.; Schlette, S.; Radtke, M.A.; John, S.M.; Zink, A.; Suthakharan, N.; Sommer, R. Translating the WHA resolution in a member state: Towards a German programme on 'Destigmatization' for individuals with visible chronic skin diseases. J. Eur. Acad. Dermatol. Venereol. 2019, 33, 2202-2208. [CrossRef]

16. Topp, J.; Andrees, V.; Weinberger, N.A.; Schäfer, I.; Sommer, R.; Mrowietz, U.; Luck-Sikorski, C.; Augustin, M. Strategies to reduce stigma related to visible chronic skin diseases: A systematic review. J. Eur. Acad. Dermatol. Venereol. 2019, 33, 2029-2038. [CrossRef]

17. Koo, J.; Marangell, L.B.; Nakamura, M.; Armstrong, A.; Jeon, C.; Bhutani, T.; Wu, J.J. Depression and suicidality in psoriasis: Review of the literature including the cytokine theory of depression. J. Eur. Acad. Dermatol. Venereol. 2017, 31, 1999-2009. [CrossRef]

18. Zink, A.; Herrmann, M.; Fischer, T.; Lauffer, F.; Garzorz-Stark, N.; Böhner, A.; Spinner, C.D.; Biedermann, T.; Eyerich, K. Addiction: An underestimated problem in psoriasis health care. J. Eur. Acad. Dermatol. Venereol. 2017, 31, 1308-1315. [CrossRef]

19. Michalek, I.M.; Loring, B.; John, S.M. Global Report on Psoriasis; World Health Organization: Geneva, Switzerland, 2016; ISBN 9241565187.

20. Armstrong, A.W.; Harskamp, C.T.; Dhillon, J.S.; Armstrong, E.J. Psoriasis and smoking: A systematic review and meta-analysis. Br. J. Dermatol. 2014, 170, 304-314. [CrossRef]

21. Brenaut, E.; Horreau, C.; Pouplard, C.; Barnetche, T.; Paul, C.; Richard, M.-A.; Joly, P.; Le Maître, M.; Aractingi, S.; Aubin, F.; et al. Alcohol consumption and psoriasis: A systematic literature review. J. Eur. Acad. Dermatol. Venereol. 2013, 27, 30-35. [CrossRef]

22. Takahashi, H.; Iinuma, S.; Tsuji, H.; Honma, M.; Iizuka, H. Biologics are more potent than other treatment modalities for improvement of quality of life in psoriasis patients. J. Dermatol. 2014, 41, 686-689. [CrossRef]

23. Maroti, M.; Ulff, E.; Wijma, B. Quality of life before and 6 weeks after treatment in a dermatological outpatient treatment unit. J. Eur. Acad. Dermatol. Venereol. 2006, 20, 1081-1085. [CrossRef]

24. Eissing, L.; Radtke, M.A.; Zander, N.; Augustin, M. Barriers to guideline-compliant psoriasis care: Analyses and concepts. J. Eur. Acad. Dermatol. Venereol. 2016, 30, 569-575. [CrossRef]

25. Schielein, M.C.; Tizek, L.; Rotter, M.; Konstantinow, A.; Biedermann, T.; Zink, A. Guideline-compliant prescription of biologicals and possible barriers in dermatological practices in Bavaria. J. Eur. Acad. Dermatol. Venereol. 2018, 32, 978-984. [CrossRef] [PubMed]

26. Schielein, M.C.; Tizek, L.; Seifert, F.; Biedermann, T.; Zink, A. Versorgung von chronisch entzündlichen Hauterkrankungen: Gehen Betroffene zum niedergelassenen Dermatologen? Hautarzt 2019, 70, 875-882. [CrossRef] [PubMed]

27. Sheikh, K.; George, A.; Gilson, L. People-centred science: Strengthening the practice of health policy and systems research. Health Res. Policy Syst. 2014, 12, 19. [CrossRef] [PubMed]

28. Starfield, B. Is patient-centered care the same as person-focused care? Perm. J. 2011, 15, 63-69. [CrossRef]

29. Arafa, A.E.; Anzengruber, F.; Mostafa, A.M.; Navarini, A.A. Perspectives of online surveys in dermatology. J. Eur. Acad. Dermatol. Venereol. 2019, 33, 511-520. [CrossRef]

30. Tizek, L.; Schielein, M.; Rüth, M.; Ständer, S.; Pereira, M.P.; Eberlein, B.; Biedermann, T.; Zink, A. Influence of Climate on Google Internet Searches for Pruritus Across 16 German Cities: Retrospective Analysis. J. Med. Internet Res. 2019, 21, e13739. [CrossRef]

31. Tizek, L.; Schielein, M.C.; Rüth, M.; Szeimies, R.-M.; Philipp-Dormston, W.G.; Braun, S.A.; Hecker, C.; Eberlein, B.; Biedermann, T.; Zink, A. Interest in Skin Cancer in Urban Populations: A Retrospective Analysis of Google Search Terms in Nine Large German Cities. Acta Derm. Venereol. 2019, 99, 797-804. [CrossRef]

32. Zink, A.; Schuster, B.; Rüth, M.; Pereira, M.P.; Philipp-Dormston, W.G.; Biedermann, T.; Ständer, S. Medical needs and major complaints related to pruritus in Germany: A 4-year retrospective analysis using Google AdWords Keyword Planner. J. Eur. Acad. Dermatol. Venereol. 2019, 33, 151-156. [CrossRef]

33. Schuster, B.; Ziehfreund, S.; Biedermann, T.; Zink, A. Psoriasis 2.0: Facebook as a source of disease-related information for patients with psoriasis. J. Dtsch. Dermatol. Ges. 2020. [CrossRef] 
34. Wartberg, L.; Petersen, K.-U.; Kammerl, R.; Rosenkranz, M.; Thomasius, R. Psychometric validation of a German version of the compulsive Internet use scale. Cyberpsychology Behav. Soc. Netw. 2014, 17, 99-103. [CrossRef] [PubMed]

35. Guertler, D.; Rumpf, H.-J.; Bischof, A.; Kastirke, N.; Petersen, K.U.; John, U.; Meyer, C. Assessment of problematic internet use by the Compulsive Internet Use Scale and the Internet Addiction Test: A sample of problematic and pathological gamblers. Eur. Addict. Res. 2014, 20, 75-81. [CrossRef] [PubMed]

36. Topp, C.W.; Østergaard, S.D.; Søndergaard, S.; Bech, P. The WHO-5 Well-Being Index: A systematic review of the literature. Psychother. Psychosom. 2015, 84, 167-176. [CrossRef] [PubMed]

37. World Health Organization. Wellbeing Measures in Primary Health Care: The DepCare Project. Available online: http://www.euro.who.int/_data/assets/pdf_file/0016/130750/E60246.pdf (accessed on 7 April 2020).

38. Löwe, B.; Spitzer, R.L.; Gräfe, K.; Kroenke, K.; Quenter, A.; Zipfel, S.; Buchholz, C.; Witte, S.; Herzog, W. Comparative validity of three screening questionnaires for DSM-IV depressive disorders and physicians' diagnoses. J. Affect. Disord. 2004, 78, 131-140. [CrossRef]

39. Mayfield, D.; McLeod, G.; Hall, P. The CAGE questionnaire: Validation of a new alcoholism screening instrument. Am. J. Psychiatry 1974, 131, 1121-1123. [CrossRef] [PubMed]

40. Dhalla, S.; Kopec, J.A. The CAGE questionnaire for alcohol misuse: A review of reliability and validity studies. Clin. Investig. Med. 2007, 30, 33-41. [CrossRef]

41. Ramsay, B.; O'Reagan, M. A survey of the social and psychological effects of psoriasis. Br. J. Dermatol. 1988, 118, 195-201. [CrossRef]

42. Patruno, C.; Napolitano, M.; Balato, N.; Ayala, F.; Megna, M.; Patrì, A.; Cirillo, T.; Balato, A. Psoriasis and skin pain: Instrumental and biological evaluations. Acta Derm. Venereol. 2015, 95, 432-438. [CrossRef]

43. Eichenberg, C.; Schott, M.; Decker, O.; Sindelar, B. Attachment Style and Internet Addiction: An Online Survey. J. Med. Internet Res. 2017, 19, e170. [CrossRef]

44. Megna, M.; Gisonni, P.; Napolitano, M.; Dell'Aversano Orabona, G.; Patruno, C.; Ayala, F.; Balato, N. The Effect of Smartphone Addiction on Hand Joints in Psoriatic Patients: An Ultrasound-Based Study. J. Eur. Acad. Dermatol. Venereol. 2018, 32, 73-78. [CrossRef] [PubMed]

45. Atzendorf, J.; Rauschert, C.; Seitz, N.-N.; Lochbühler, K.; Kraus, L. The Use of Alcohol, Tobacco, Illegal Drugs and Medicines. Dtsch. Arztebl. Int. 2019, 116, 577-584. [CrossRef] [PubMed] 